\title{
RE-READING, RE-WRITING, RE-CONTEXTUALISING SHAKESPEARE
}

This is the title of a conference and of two subsequent issues of LINGUACULTURE, both testifying, among other things, to the extraordinary impact Shakespeare's works still have on present-day scholars, even if their interests involve complex discursive operations which range from minute historical documentation to adjustment, translation, adaptation, replacement and re-interpretation of his texts. This second issue of LINGUACULTURE, dealing with the same topic as the previous one, continues the potentially endless series of dialogues with Shakespeare's texts which, as will be seen, have been either re-read, re-written, reconsidered as such, or have served as mere starting points for more radical transformations and rewritings.

Despite the diversity of approaches, the articles in this journal have been grouped according to some unifying concerns with historically and culturally recontextualizing Shakespeare's plays, re-reading his female characters, rediscussing his language or re-writing his texts so as to serve purposes which have sometimes turned out to be completely different from the author's initial intentions.

Some of these aspects are present in Marta Gibinska's opening article on Shakespeare's cultural diversity. In her opinion, there are some salient features which make Shakespeare so unique both in his own culture and in world literature. One of them is his language, which preserves past accumulations while also introducing new highly creative words and turns of phrase. Such is the power of Shakespeare's words, Gibinska claims, that quotations from his plays and reverberations of his characters' monologues can still be found in all kinds of contemporary texts and discourses. Another feature worthwhile considering is Shakespeare's perception of history not only in terms of providing information about historical figures and events, but also, and more significantly, of teaching his readers and audience how to better understand their own position and sense of identity in interpreting history. In the author's view, the ultimate great lesson Shakespeare has taught humanity regards human nature, as his characters are mirrors in which we recognize ourselves, as social beings and individuals. A series of illustrations from Twelfth Night, As You Like It, Hamlet and Macbeth are convincing demonstrations of the ways in which Shakespeare reveals, through his characters, disquieting truths about ourselves, about "the 
bottomless sea of human nature", about the tragic gap existing between appearance and reality, between who people think we are, who we think we are, and who we 'really' are. Finally, Marta Gibinska's last argument in favour of Shakespeare's cultural diversity and belonging to the world's heritage is the impressive number of translations his works have spawned at different times in history, in so many different target cultures. At the same time, the very high number of translations which has ensured Shakespeare's immortality confirms the truth of Ben Jonson's well-known statement that "[Shakespeare] was not of an age, but for all time!" and, we could add, from this all-encompassing translation perspective, for all cultural and geographical spaces.

The series of papers that follow concentrates, in an even more concrete manner, on the ways in which Shakespeare's works were historically and geographically re-contextualized. In Robert Horton's and Kath Bradley's articles these re-contextualizations involve more complex operations, not only of temporal and spatial dislocation but also of intersemiotic translations into particular films and plays in which the Shakespearian reader's own cultural identity or a very specific political situation may play a very important part.

Particularly in Chimes at Midnight (1965), Horton's 'reader' of Shakespeare, Orson Welles, actor and film director, is shown to approach the Bard with what the author of the article considers to be "a mix of bravado and insecurity". This paradoxical attitude finds both a cultural and a more specific colonial explanation, since Welles's American identity is not deprived of colonial overtones. Even if Welles plays Falstaff in the film, the script of which contains texts from five Shakespearian plays, Henry IV, Part 1 and Henry IV, Part 2, Henry $V$ as well as Richard II, his identification is shown to be not only with his role but also with Prince Hal's. Through thick contextualization and close interaction with Welles's biography, Horton establishes, on the one hand, analogies between Prince Hal's anxieties about the English throne and the American film director's nervousness about being accepted by a British audience. On the other hand, though, Welles's irreverence with regard to Shakespeare is shown to materialise, among other things, in the very re-shaping of various Shakespearian texts into one script or, from a more technical, filmrelated perspective, in a tendency to speed up the action, "to keep things briskly moving along" to the detriment of the monologues that are so important in the original plays. The final result of all this is, nevertheless, a film that has come to be regarded by many as a climactic point in Welles's artistic career.

(Re)Contextualization is also a key word in Kath Bradley's article, which addresses Barbara Gaines's re-shaping of Shakespeare's historical plays in her trilogy entitled Tug of War: Foreign Fire, and particularly in Edward III, its opening section. However, many references are also made to Gaines's second war trilogy [Tug of War: Civil Strife]. Bradley's contribution more specifically consists in a closer examination of presentism in this performance, which is 
linked not only to the aggressive policies carried out by the United States in the last decades but also to a clearly defined moment in the political life of the country, the 2016 presidential election. Bradley's research mainly draws on the consultation of a - frustratingly - limited archival material, in view of the ephemeral quality of these theatrical events: mainly American reviews, and a (highly important) British one, as well as a personal interview and emails with Gaines, the author of this theatrical project and Artistic Director of the Shakespeare Theater of Chicago. The presence of the collaborative play Edward $I I I$ at the very beginning of the first trilogy is justified by its message, which is in keeping with Gaines's own intention to expose "the cyclical and wasteful nature of war". Besides the Shakespearian texts as such, other elements such as live rock music appear to be extremely effective in conveying the main themes of the plays, e.g. pointless waging of wars in which young people die, impact of wars on the lives of the common people, etc. Bradley aptly notices that relatively few reviewers had the time to approach the presentism of the trilogy, a notable exception being Michael Billington, the British theatre reviewer of The Guardian, the only journalist to openly discuss the producer's anti-imperialist protest through the Shakespearian collage and adaptations. In fact, the interviews and emails give Bradley direct access to Gaines's militant intentions enabling her to notice a gradual shift of focus from a more general anti-imperialist message to the (more specific) presidential election. One significant example in this respect is shown to be that of the battles fought without weapons testifying to the producer's pacifist message in opposition to the ongoing debates around the Second Ammendment supported by Trump. In such cases Shakespeare's texts are, no doubt, manipulated so as to serve a particular political cause and context but, as Bradley realizes, the ellusive nature of theatrical performances makes it difficult to retrieve this context and preserve the refracted message for posterity.

Daniela Doboss re-contextualises Shakespeare in Romania, back in the early 1940's. through the exemplary case study of the playwright, essayist, journalist and novelist of Jewish origin Mihail Sebastian. Drawing on two accurate documents that trace Sebastian's acquaintance and dialogue with Shakespeare, the writer's own Journal written between 1935-1944, and posthumously published in 1996, and translator Petre Solomon's memoir of the 1923-1947 period, published in 2016, containing his notes taken down at Mihail Sebastian's course on Shakespeare's sonnets, Doboş attempts to explain Sebastian's keen, almost obsessive interest in Shakespeare in the last, most difficult years of his life. In fact, as she shows, it was during the Second World War that Sebastian started learning English and, very soon, he was reading and translating from English and American canonical authors, Shakespeare included. Sebastian's interaction with Shakespeare is thus related to a time when Fascist ideas had penetrated the Romanian political scene and had materialized in the 
Iron Guard, an ultra-nationalist and anti-semitic far right movement, which closely followed Hitler in its wish to exterminate Jews. On a personal level, Sebastian found himself betrayed by his best friends who avoided his company having adopted the Fascist ideology. His plays were no longer performed and, in the early 1940's, he could only teach in the private schools for Jews that had been set up in Bucharest. Analysing the writer's own confessions in the Journal, as well as Solomon's testimonies, Doboş sees Sebastian's increasingly high interest in Shakespeare's plays and sonnets as well as his teaching of Shakespeare's sonnets as the result of the soothing effect the Bard's works had on his tormented psyche in those years. In her opinion, like many other readers Sebastian could identify himself with many of Shakespeare's tragic characters, his general mood still remaining one of enchantment with the Shakespearian texts. Sebastian's preference for the sonnets as teaching materials is further explained through the identity theme which prevails in the sonnets and was very much a matter of concern at a time when the Jews' identity was very much at stake. In addition, by comparing some of the Shakespeare-related criticism of the time with Sebastian's occasionally minute interpretations of the sonnets as presented by Solomon in his memoir, Dobos highlights the original elements in Sebastian's approach to Shakespeare, which was not, occasionally, deprived of critical overtones. Consequently, the author of the article claims, the image of Shakespeare that is projected through Sebastian's response to his works is far enough from the romantic one of an unquestioned genius and closer to one of a 'real' man. Ultimately, Sebastian's readings of Shakespeare seem to be mainly concerned with the characters' search for identity, in the same way in which Sebastian was looking for his own.

But Shakespeare has also been contextualised in a more retrospective manner. In so doing, Klára Škrobánková addresses both the factors 'time' and 'literary genre', as she discusses the transformations undergone by some of Shakespeare's plays (Henry IV, Part One, A Midsummer Night's Dream, Hamlet, and Venus and Adonis) into farces and drolls that were published first in Henry Marsh's, then in Francis Kirkman's collection The Wits or Sport upon Sport, in three successive editions during the Restoration period, in 1662 (first edition), 1672 (second edition) and 1673, when the second volume of the collection was also published. At first sight, transforming comedies and tragedies into 'farces' or 'drolls', by cutting out only the comical scenes of Shakespeare's (as well as other Elizabethan or Jacobean authors') plays appears to be a downgrading operation, especially in comparison with the loftiness of the Shakespearian drama. As Škrobánková notices, in the first edition the original authors' names were not even mentioned and, apart from Robert Cox, an actor and droll contriver, no other names of such 'adaptors' were included ether. Through this conversion of 'higher' literary genres into drolls, great Shakespearian characters came to be overshadowed by a noisy group of clowns 
in what appeared to be either funny, vulgar, rude or downright lewd scenes. However, the argumentative line of the article follows a different direction. Škrobánková's point is not to insist on drolls as forms of theatrical regression. On the contrary, by minutely describing the changes undergone by every Shakespearian play converted into a droll in Kirkman's collection, she shows that, in the specific historical context of the Restoration period, this new genre had its own cultural importance. At a time when the theatres were officially closed, new conventions were also imposed: one of them relates, for instance, to the apolitical nature of the texts to be published, a norm that is, nevertheless, shown to have been subtly undermined through the soldier comical figures present in the drolls - of which Falstaff was among the most salient. All in all, the article convincingly demonstrates that the main function of these written texts and ensuing performances was to provide comic relief, sometimes at considerable costs, in view of the questionable legitimacy of the whole enterprise, not only for common people but also for the upper classes. Moreover, as the example of The Merry Conceited Humours of Bottom the Weaver based on A Midsummer Night's Dream proves, the conversion of the play into a droll implied more than the mere extraction of farcical elements, also including scenes with the fairies, Titania, Oberon, and Puck. Even if, as Škrobánková's analyses demonstrate, Shakespeare's popularity seems to have consistently declined during the period under discussion, the droll The Bouncing Knight inspired from Henry IV, Part One remained, nevertheless, a favourite among the interregnum theatre-goers. In a sense, and paradoxically so, as the article proves, despite this decrease in popularity, drolls nevertheless contributed to the survival of Shakespeare's name and fame during a difficult period in the history of the British drama.

Sorina Postolea and Lorelei Caraman's paper addresses a more familiar direction in literary criticism on Shakespeare, i.e. the [animal] imagery of his plays, a topic that they, nevertheless, approach through new methods of investigation, which assign more rigor and precision to their findings. Drawing on a corpus of 185 like-comparisons which involve animals, extracted from the 1916 Oxford University Press edition of Shakespeare's plays (consisting of 17 comedies, 10 tragedies, and 10 historical plays), the authors' purposes are manifold: from detecting the author's preference for certain types of animals and the functions they fulfil in the plays to more general - and more significant conclusions relating to the links that are established between the human and the animal component and, ultimately, between anthropocentrism and anthropomorphism in Shakespeare's plays. Thus, from this very special kind of re-reading Shakespeare through recurrent animal imagery framed in likecomparisons, several interesting conclusions are drawn with regard to the playwright's perception of the human-animal associations. The authors' quantitative analyses reveal no less than 102 different animals (mammals, birds, 
fish and water animals, insects and worms, reptiles and amphibians, fantastic, mythological, or invented, the order of enumeration is significant as well) that populate the plays, a total figure which is further refined through subdividing categories, e.g. mammals predominate, but the preference is for domestic animals, from among which dogs and horses prevail, etc.

Obviously, more detailed research along these lines could turn into entire books, as the authors also realize. They could be correlated to previous critical investigations and provide even more in-depth interpretations for these challenging quantitative findings. The most significant conclusions of the paper are, perhaps, the ones relating to Shakespeare's attitudes to the animal world and, ultimately, to the relationship between anthropocentrism and anthropomorphism in his plays. According to the analyses, as far as the former aspect is concerned, negative attitudes to animals exceed in number more 'positive' or neutral ones, thus supporting the idea of Shakespeare's fundamental anthropocentrism. This is in keeping with the authors' expectations to find in the plays one of the most cherished Renaissance ideals relating to the supremacy of man over 'the beast', to humanism as an overarching principle. However, the data provided by the corpus allow the authors to detect not only negative but also positive associations between the world of the humans and that of the animals, to grasp a less visible, yet present tendency towards anthropomorphism that undercuts the texts, a thing which once again confirms the richness and complexity of the Shakespearian message.

Cristina Diamant and Simona Avarvarei's respective contributions share in common an interest in throwing new light on some unconventional female characters in Shakespeare's sonnets, A Midsummer Night's Dream and Macbeth.

Cristina Diamant sets her paper, Hermia and the Dark Lady: From Perceived Others to Potential Erotic Objects, against realities that confront our world directly: a very vocal reactionary attitude to globalism, that reshapes the map of political alliances, blurs the understanding of the demographic, economic and even religious realities of our millennium and, in the author's words, "makes the process of othering possible". In such a context, a discussion about characters such as the Dark Lady or Hermia might prove to be quite revealing, as it offers a possible answer to a question that is fundamental not only from a literary point of view, but also from a more general, sociological one: "Should dark ladies, such as the mysterious one who inspired his sonnets, or Hermia of $A$ Midsummer Night's Dream be completely othered?" Diamant suggests that, given the centrality of such characters in the text, it is the opposite that appears to be more plausible. These characters are the driving forces in their respective stories, and not "a threat to the social order." It is hard to emphasize enough how important a redefinition of beauty is in our contemporary world if we think, for instance, that only two years have passed since one major ballet company 
accepted the idea that a leading ballerina should not necessarily be white or frail (sometimes pathologically so) and, in the end, that a strong, dark, curvaceous talented lady (Misty Copeland, in our case) could take the lead in a company without damaging the mythos of the classical ballet dancer.

More than four hundred years ago Shakespeare had already refused both to set barriers of difference and to beautify his characters. Authenticity is what he seeks, as he speaks "of a crude true love for authentic women." This takes him on a solitary and revolutionary path in a literary "tradition of conceit." The author gives relevant contrasting examples to underline this implied conflict with the cultural tradition. Shakespeare's very human "My mistress, when she walks, treads on the ground" has practically nothing in common with Petrarch's idealizing lines, "[s] he did not walk in any mortal way/ But with angelic progress..." On the other hand, the Dark Lady and Hermia become, in themselves, "innovative definitions of beauty." In Diamant's view, such characters are not only an instance of political correctness avant la lettre, but Shakespeare's authentic and unapologetic admiration for beauty, that can also be traced in an earlier play, Love's Labour's Lost: "Is ebony like her? O wood divine..."

Simona Avarvarei takes us to a different kind of female strangeness. Her purpose in approaching Shakespeare's Macbeth is to re-read and analyse the different cultural facets of the "Weird Sisters" in an attempt to "map the meandering expression of otherness when womanhood constructs an epiphanic encounter with time and fortune". The witch is seen here as an epiphenomenon. Quoting Diana Purkiss, the author claims that in the rural tradition, the witch is a construct (the "antihousewife," the "antimother") that allows women to deal with their fears and anxieties, when they feel threatened in their roles as wives and mothers. Thus, a social phenomenon, a reality where "the law of the father" rules, the witches, these "[p]hantasmal figments, suspended above time itself, sometimes ethereal and yet, often enough, imprisoned in maimed expressions of dry and rotted flesh" are called into existence.

When it comes to the representation of witches, Avarvarei distinguishes between two traditions: the Scottish one, which bears similitudes with the Continental folklore, and the English tradition. Mischievously cackling witches that are part of a coven, a sort of sorority, standing round a cauldron, are specific to the Scottish tradition but are "hardly found in English witch-stories". This brings the author to the conclusion that, although Shakespeare found his inspiration in an "elite" tradition (Raphael Holinshed's Chronicles of England, Scotland and Ireland of 1577), it is the Scottish folk tales that give the image of the three Weird Sisters: "filthy, ragged, warty, ugly old women", that is women that function, for the ordinary people of the time (but not only), very much the way Lilith does, in other cultures. In fact, one very interesting aspect of this study is the parallel Avarvarei draws between the three sisters and their 
equivalents in the Greek, Roman, but also Norse mythologies. In ancient Greece, the characters who could dictate a mortal's fate were the three Moirae - Clotho, Lachesis and Atropos. The Roman tradition tells us about "three Parcae or Fata - Nona, Decima, and Morda". However, the Norse mythology is more telling in this context, as the word "weird", "seldom used in Elizabethan English, comes from the Old English, meaning 'fate' or 'destiny,' thus having no connection with today's connotation of 'strange' or 'bizarre." This brings critics to the conclusion that Shakespeare was familiar with the Norns, the Norse goddesses of destiny, the "three sisters wyrd", Urdr, Verdandi, and Skuld. Other facets of the same topic - numerological or anthropological - are also discussed.

Andreea Șerban and Alina Bottez move one step further on the scale of response to Shakespeare's works, replacing the (mere) re-readings of his texts by the examination of more complex operations of rewriting, recontextualisation, adaptation, intersemiotic translation and, ultimately, transformation of the 'initial' play.

Andreea Serban focuses on three different manga versions of Romeo and Juliet, in order to explore several representations of space. Although the author insists on the city of Verona itself, on the Capulet ballroom, and Juliet's bedroom, she also discusses the linguistic space, noting captivating differences between the three versions analysed (chronologically, a British manga version from 2007, an American one, published the next year, and finally a Japanese one, released in 2010, "following the success of an anime (animated film) version entitled Romeo X Juliet". She notes that "the British version uses Shakespeare's original language in an abridged form", the American version "employs Shakespeare's original language, occasionally shortened", while "the Japanese version uses modern English sprinkled now and then with archaic words." The shapes of the speech bubbles are also contrasted: "irregular in shape, sometimes even without any outline" (British version), "round or oval speech bubbles sometimes replaced by irregular or cloud-shaped balloons" (American version) and "predominantly irregular speech balloons" in the most recent of the three versions, the Japanese one. Of course, one significant difference between the British and American versions on the one hand and the Japanese one on the other is the way we read the books: from left to right in the case of the western versions, and from right to the left of the page when it comes to the Japanese manga books, "as is traditional for this culture and genre." A western reader is thus defamiliarized by such an exercise and becomes more aware of cultural differences when confronted with a totally new way of perceiving the space of the page and the text on it.

The city, in the three versions chosen by Serban as examples, is different. The British one moves the plot to modern-day Tokyo, the American manga keeps the setting in Renaissance Verona, while "the Japanese version moves the setting to an alternative universe, where the city of Neo Verona has 
developed on a floating island." The ballroom, on the other hand, however different it might be in the three versions, retains one obvious constant: "its western aristocratic look". As for the last space analysed in the study, Juliet's bedroom, "the most intimate space in the whole play/manga", the author contrasts again the first two versions to the Japanese one, noting that in this last instance "Juliet's bedroom retains its female gendered aspect, remaining untainted by male intrusion."

With all these differences minutely described by Andreea Șerban, the paper concludes with Stephen Greenblatt's words: "new Shakespearean spaces such as those in the three manga versions may be real or deceptive, but they definitely "open his plays to the possibility of ceaseless change."

If Andeea Șerban takes us in the world of manga, in her article Alina Bottez analyses the way "opera and musical reread Elizabethan drama shifting from spoken to sung discourse." Her ambitious endeavour takes us on a transnational, transtemporal and even transgender and transreligious journey. Different cultural contexts, the conventions of the lyrical theatre, or social and political factors, as well as reception dictate the transformation of the Shakespearean works.

In the re-contextualisation of gender according to vocal traditions, we are travelling through time from the "barbarous practice of the castrati" to our contemporary countertenors, but also to the "vocal travesty: male roles started being interpreted by women, especially mezzosopranos" - with the excellent example of Bellini's I Capuleti e i Montecchi, "where Romeo, the emblem of romantic male love par excellence, is interpreted by a mezzosoprano." Moreover, during the sexual revolution of the sixties, "homosexual composer Benjamin Britten writes his superb opera A Midsummer Night's Dream, while his lifelong partner Peter Pears helps him write the libretto." Here, "the part of the fairy-king Oberon, the epitome of male power and even macho vanity in Shakespeare's play is written for a countertenor."

Alina Bottez also traces a brief history of the rewriting of religion in different moments in time and in different cultures. We travel through spacetime from Shakespeare, "known to have oscillated between elements of Catholic and Protestant faith, which is illustrated especially in Hamlet," to Gounod's nineteenth century "staunch Catholicism," but also to the Greek orthodox sonorities in Pascal Bentoiu's Hamlet, and to the adaptation of Romeo and Juliet into Leonard Bernstein's musical West Side Story, where "all hint at Christianity is erased."

Sometimes cultural barriers have to be overcome: "the English, French and Welsh verbal fun in The Merry Wives of Windsor ... is metamorphosed into Germ-Italian in Salieri's Vienna." Sometimes the results are catastrophic, and Alina Bottez comes with a radical example, that of Ambroise Thomas's Hamlet. 
Here, she quotes Emmanuel Chabrier's witty remark that "There is good music, there is bad music and there is... Ambroise Thomas."

In the case of these operatic transmediations, like in that of the manga books, Shakespeare's works find new artistic possibilities and reach an even larger audience.

All in all, the scholars whose papers are included in this issue of LINGUACULTURE come from different cultures and countries, share a common love for and interest in Shakespeare's work, from which they select highly different texts and resort to highly different methods of investigation. Although inevitably limited in number, these studies take us a long way from the 'originals' in their home culture, to mid-twentieth century Romania, to Orson Welles in the 1950's or the 2016 American elections, to Japanese contemporary manga or...to the opera, at different times in history, once again testifying to the amazing plurality of response Shakespeare's works have received. In addition, as is well known, these studies are all tiny fragments of the same gigantic puzzle that is called Shakespearian scholarship. The editors of this issue hope that the readers will find here new stimulating pieces of information in a field that will never cease to fascinate us. 